This item was submitted to Loughborough's Research Repository by the author.

Items in Figshare are protected by copyright, with all rights reserved, unless otherwise indicated.

\title{
Impact and observations of cylinder deactivation and reactivation in a downsized gasoline turbocharged direct injection engine
}

\author{
PLEASE CITE THE PUBLISHED VERSION
}

https://doi.org/10.1177/1468087419882817

\section{PUBLISHER}

SAGE Publications

VERSION

AM (Accepted Manuscript)

\section{PUBLISHER STATEMENT}

Users who receive access to an article through a repository are reminded that the article is protected by copyright and reuse is restricted to non-commercial and no derivative uses. Users may also download and save a local copy of an article accessed in an institutional repository for the user's personal reference. For permission to reuse an article, please follow our Process for Requesting Permission. This paper was accepted for publication in the journal International Journal of Engine Research and the definitive published version is available at https://doi.org/10.1177/1468087419882817.

\section{LICENCE}

CC BY-NC-ND 4.0

\section{REPOSITORY RECORD}

Parker, Matthew, Changzhao Jiang, Daniel Butcher, Adrian Spencer, Colin Garner, and Dennis Witt. 2019. "Impact and Observations of Cylinder Deactivation and Reactivation in a Downsized Gasoline Turbocharged Direct Injection Engine". Loughborough University. https://hdl.handle.net/2134/9944183.v1. 
Standard Article

Corresponding author:

Adrian Spencer, Loughborough University, Loughborough.

Email: A.Spencer@lboro.ac.uk

\title{
Impact and observations of cylinder deactivation and reactivation in a downsized gasoline turbocharged direct injection engine
}

\author{
Matthew C Parker, Changzhao Jiang, Daniel Butcher, Adrian \\ Spencer*, Colin P. Garner, Dennis Witt.
}

\section{Abstract}

Cylinder deactivation, sometimes referred to as Variable Displacement Engine (VDE) technology, is a method being employed in state-of-the-art reciprocating engines to improve fuel economy. The approach involves disabling the valve actuation of one or more cylinders to deactivate them, thus forcing the engine to operate at a higher specific load across the remaining cylinders to produce the torque demanded. Operating at such a point with an increased throttle opening reduces the engine's pumping losses and hence reduces fuel consumption. In this work, the spray morphology, combustion and emissions of a three-cylinder downsized gasoline turbocharged direct injection (GTDI) engine with VDE capability on one cylinder were studied. This investigation allowed the interaction between the fuel spray, engine performance and emissions immediately following the reactivation of the deactivated cylinder to be better understood. Three operation modes were examined which included running the engine at full displacement, at the reduced displacement and at full displacement with increased indicated mean effective pressure (IMEP), matching that of the reduced displacement mode. The study showed that cylinder deactivation significantly reduced specific fuel consumption at the conditions tested in comparison to full displacement operation. It was also found that when running the engine at full displacement but with the reduced displacement level IMEP, the specific fuel consumption was greater than for reduced displacement operation. In addition, it was observed that particulate number $(\mathrm{PN})$ emissions increase transiently during the deactivation period due the disturbances to the fuelling control caused by displacement transitions. Improved fuelling control, refinement of the engine calibration during reduced displacement operation or a Gasoline Particulate Filter (GPF) could be used to manage this PN level.

\section{Introduction}

With a growing global need and increased legislative pressure to reduce $\mathrm{CO}_{2}$ emissions from ground vehicles, research and development in the automotive industry has been extremely active in recent years, including the development of increased efficiency internal combustion (IC) engines. This development drive has led to downsized turbocharged Direct Injection Spark Ignition (DISI) engines to reduce $\mathrm{CO}_{2}$ emissions whilst maintaining the levels of other gaseous emissions at acceptable levels. The concept involves reducing 
the displaced volume of a typically sized engine for a given power output and matching that output through the use of direct injection, turbocharging and other additional technologies, such as variable valve timing. The concept results in a smaller engine, which operates at a higher specific load than a conventional counterpart of the same output and thus achieves a greater efficiency.

The use of cylinder deactivation is one of the potential technologies which can be used to complement the DISI engine concept and reduce fuel consumption. By deactivation of one or more cylinders of a multi-cylinder engine, the operation of the engine is shifted to a higher specific load point in order to produce the same overall torque and power output. This reduces the pumping loss of the operating cylinders and therefore reduces fuel consumption. The deactivation of the cylinder is instigated where the demanded torque output of the engine can be acceptably achieved with a portion of the available engine capacity. During the deactivation period, the intake and exhaust valves are closed to trap either hot spent or fresh charge in the cylinder. The trapped gas then acts as a "gas spring", theoretically returning the work extracted from the crankshaft in compressing the cylinder contents; in reality, there is a small thermal and frictional loss, which must not negate the fuel consumption benefit of initiating the VDE mode. Allen et. al. ${ }^{1}$ found out in their study that due to blow-by around the piston rings and heat loss through cylinder walls, cylinder pressures for combusted charge and fresh charge converge within a second. Therefore, the performance difference of trapping combusted charge or fresh charge is negligible.

Many studies have been reported addressing the impact of cylinder deactivation in terms of efficiency and emissions. Almost all of these found that cylinder deactivation significantly reduced fuel consumption under part load operation ${ }^{2-9}$. The improvement in fuel economy for vehicle running under driving conditions was also examined by Abas et. al. ${ }^{10}$. In their research, a 25.4\% BSFC improvement was seen at engine speeds of $1500 \mathrm{rpm}$ and vehicle speed of $40 \mathrm{~km} / \mathrm{h}$. In terms of the impact of cylinder deactivation on emissions, Kuruppu et. al. ${ }^{4}$ found that cylinder deactivation on gasoline engine has negative impacts on $\mathrm{CO}$ and $\mathrm{NO}_{\mathrm{x}}$ in certain cases. However, Zammit et. al.'s work ${ }^{5,6}$ showed that cylinder deactivation could be used as an effective strategy for reducing soot, $\mathrm{CO}$ and $\mathrm{HC}$ at a given $\mathrm{NO}_{x}$. Moore et. al. ${ }^{11}$. examined the use of ethanol in a deactivated engine It was found that valve deactivation could improve combustion stability and efficiency at low load for ethanol blends. Allen et. al. ${ }^{12}$, Ramesh et. al. ${ }^{13}$ and Ding et. al. ${ }^{14}$ studied the impact of cylinder deactivation on fuel efficiency and aftertreatment performance of diesel engines. They found that cylinder deactivation leads to $5 \%$ to $40 \%$ fuel consumption reduction and $50 \%$ of $\mathrm{NO}_{\mathrm{x}}$ reduction. This was due to better thermal management in deactivation mode. These researchers had examined the impacts of cylinder deactivation on various aspects such as fuel economy and emissions; however, to the best of the authors' knowledge, no research has been reported showing imaging of the deactivation and reactivation processes inside a production engine in order to understand the links between the optical observations and the emissions.

The study presented in this paper investigates the impact of cylinder deactivation on engine performance and emissions in the Ford 1.03 -cylinder Ecoboost engine. Particulate Number (PN) was the focus of the work, measured using a Cambustion DMS-500 particle mobility analyser, and gaseous emissions were also measured using a Horiba Mexa-7100. Tests were conducted under three different operation modes in order to investigate the impact of cylinder deactivation. Optical observations were made inside the cylinder using laser 
illuminated borescope imaging in order to understand the link between the spray, combustion and emissions during the cylinder deactivation and reactivation events. Understanding gained in this study can aid the design of the engine strategies during VDE events.

\section{Experimental setup and methodology}

\section{Experimental setup}

A borescope-accessed version of the Ford EcoBoost Upgrade engine was developed in order to visualise the in-cylinder environment of the VDE cylinder, i.e. the cylinder that was capable of being deactivated. This approach would allow the in-cylinder conditions during the deactivated running of the cylinder as well as the spray morphology and combustion processes post reactivation to be visualised, by capturing high speed video to compare alongside measured engine performance and emissions data.

The approach to gaining borescope access to the engine is illustrated in Figure 1, for the existing production version of the engine. The approach of using borescope access on a production engine, rather than developing a dedicated optical engine, ensured the fastest configuration time and the ability to operate the engine under real thermal conditions. The modification to the engine involved two drillings being machined through the engine's timing belt cover and cylinder head, into which access sleeves were bonded. One of these acted as the entry point for the borescope assembly itself and the other for a quartz guide rod to deliver illumination into the cylinder. In figure 1 (b) and 1(c) the upper tube is in the plane of both the cylinder axis and the crank axis and was used for borescope access. Thus, the field of view was symmetric about the cylinder centreline. The lower illumination tube (in each figure) was brought in at a compound angle and was able to fully illuminate the field of view with its delivery optic.

Imaging in this way from a running engine introduced several technical challenges associated with the durability of the borescope assembly, including protection from vibration as well as cylinder pressure and temperature. In addition, the mounting of the camera to minimise motion relative to the engine was an important development area, as was selection of suitable illumination and development of a method of recording timesynchronised image and pressure data. 

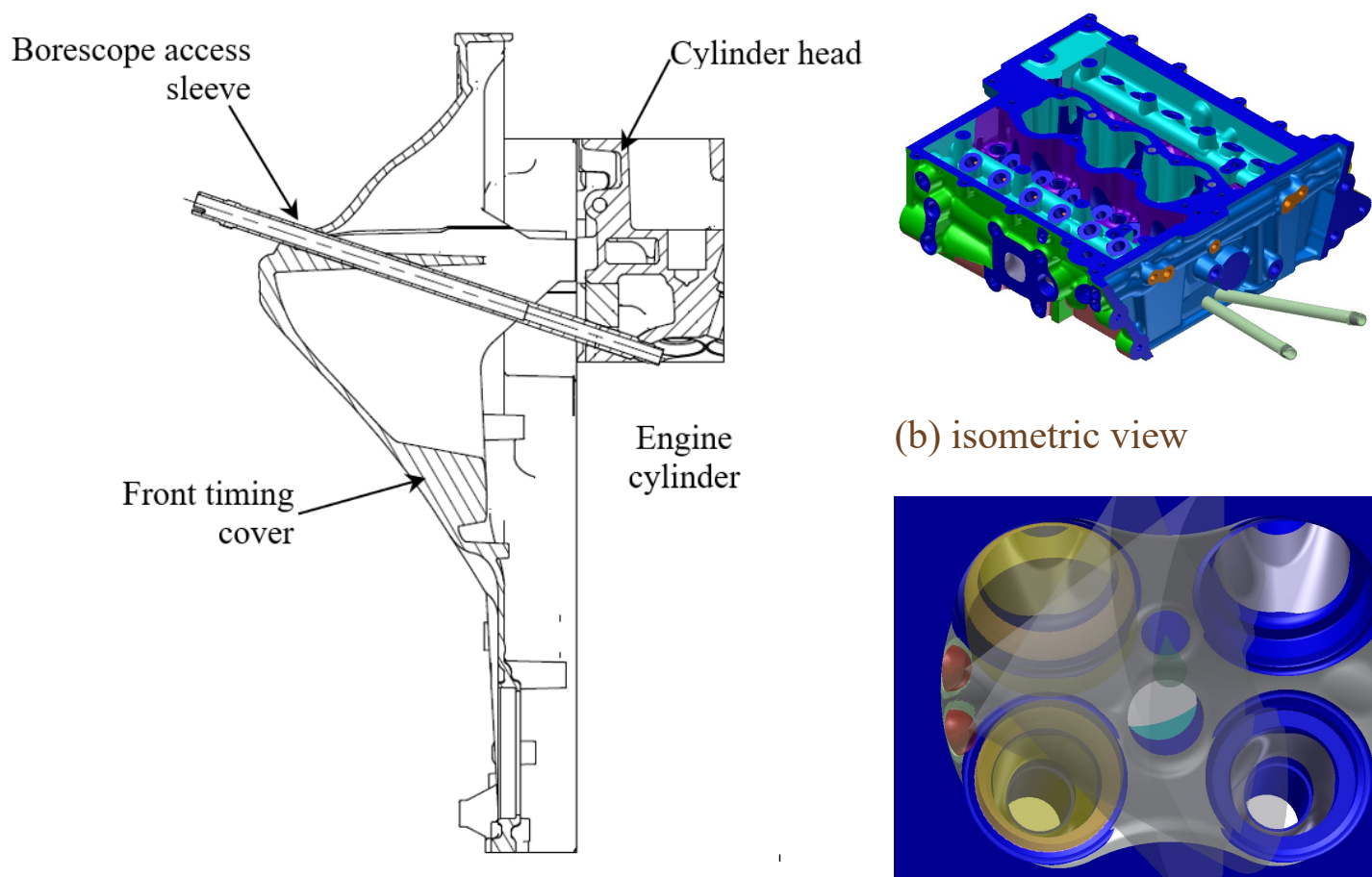

(b) isometric view

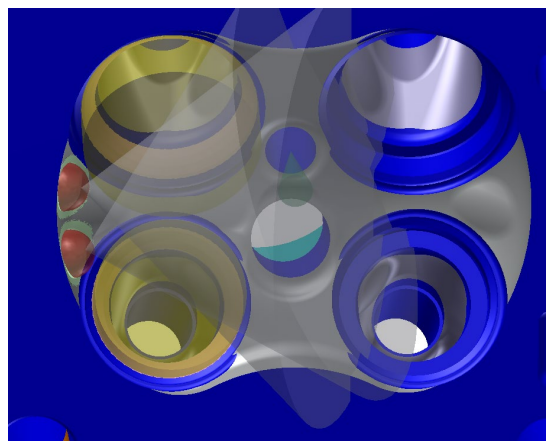

(a) cross section

(c) illumination (lower cone) and field of view (upper cone)

Figure 1- Drawing of borescope access into the engine cylinder

The full hardware configuration, including illumination system, emissions analysers, and control and data acquisition hardware is illustrated in Figure 2, with communication and acquisition lines also highlighted. The detail of the hardware items are listed in Table 1. The hardware configuration described allowed the collection of engine performance data, including in-cylinder pressure and engine output torque as well as the recording of engine out gaseous and particulate emissions. The system also facilitated the illumination and capture of high speed in-cylinder video. 


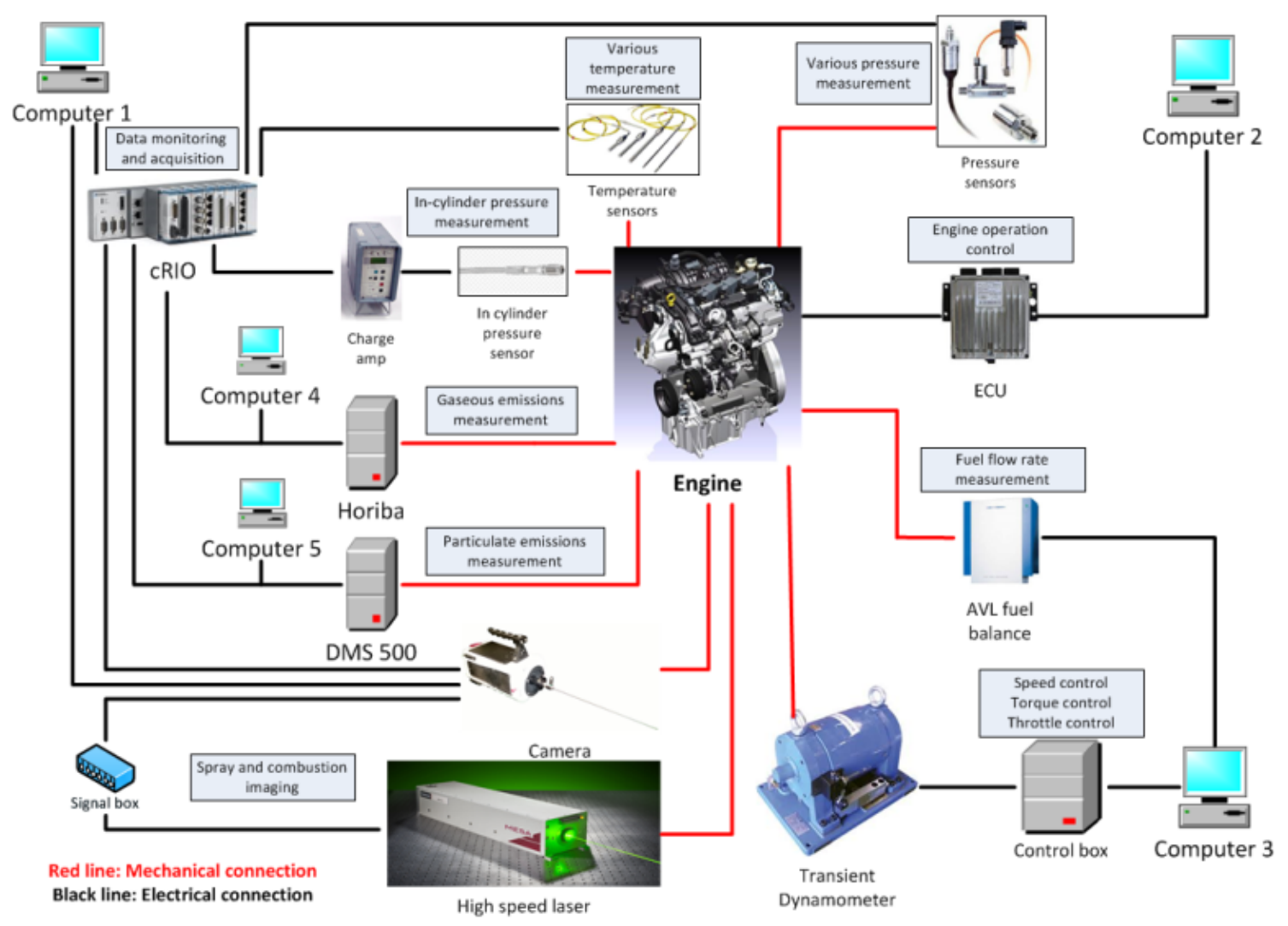

Figure 2 - Schematic of test cell configuration for borescope imaging

Table 1 - Experimental hardware

\begin{tabular}{|l|l|l|}
\hline & Parameter & Value \\
\hline Engine: & Displacement & $1.0 \mathrm{l}$ \\
& Number of cylinders & 3 \\
& Peak power & $92 \mathrm{~kW}$ \\
& Peak torque & $170 \mathrm{Nm}$ \\
\hline Camera: & Frame rate (@ resolution) & $20,000 \mathrm{fps}$ (@ 512 x 512) \\
Photron AX200 & Bit depth & $12 \mathrm{bit}$ \\
\hline Laser: & Manufacturer & Lee Laser \\
& Type & Nd:YAG \\
& Wavelength & $532 \mathrm{~nm}$ \\
& Pulse energy/duration & $3 \mathrm{~mJ} / 200 \mathrm{~ns}$ \\
& Repetition rate & $10 \mathrm{kHz}$ \\
\hline Dynamometer & Description & \\
\hline Powertrain control unit & Fully transient AC dynamometer \\
\hline Data acquisition / controller & PCM with user adjustment via ATI \\
\hline Gaseous emissions & LabView and NI Compact RIO (cRIO) \\
\hline Particulate emissions & Horiba Mexa-7000 \\
\hline Fuel consumption & Cambustion DMS500 \\
\hline
\end{tabular}




\section{Experimental methodology}

High speed video and all recorded data were captured at three different engine conditions, which are given in Table 2. Test condition 1 represented normal operation of the engine, with full displacement operating at $1600 \mathrm{rpm}, 30 \mathrm{Nm}$ torque output. Through use of an ATI memory emulator interface onboard the Powertrain Control Module (PCM), the VDE system could be activated (whilst the dynamometer load and speed demand remained fixed), in the case of condition 2, in order to test the engine operating at reduced displacement, whilst targeting the same engine output as condition 1. Condition 3 then tested the engine at full displacement whilst matching the IMEP condition 2, thus producing a higher output torque. This operating point has been chosen for investigation here because it is a typical condition when VDE strategy would be employed. With relatively low IMEP the thermal and pressure loading on the optical equipment at this condition also helped with reliability of the measurements.

Table 2 - Test conditions

\begin{tabular}{|c|c|c|c|c|c|}
\hline $\begin{array}{l}\text { Test } \\
\text { condition }\end{array}$ & $\begin{array}{l}\text { Engine } \\
\text { speed } \\
\text { (rpm) }\end{array}$ & $\begin{array}{l}\text { Target } \\
\text { torque } \\
\text { (Nm) }\end{array}$ & $\begin{array}{l}\text { Measured } \\
\text { torque } \\
\text { (Nm) }\end{array}$ & IMEP (bar) & $\begin{array}{l}\text { Average } \\
\text { IMEP } \\
\text { (bar) }\end{array}$ \\
\hline 1 & 1600 & 30 & 31 & $\begin{array}{l}\text { Cylinder 1: } 4.58 \\
\text { Cylinder 2: } 4.58 \\
\text { Cylinder 3: } 4.89\end{array}$ & 4.68 \\
\hline 2 & 1600 & 30 & 27 & $\begin{array}{l}\text { Cylinder 1: N/A } \\
\text { Cylinder 2: } 6.30 \\
\text { Cylinder 3: } 6.17\end{array}$ & 6.37 \\
\hline 3 & 1600 & N/A & 44 & $\begin{array}{l}\text { Cylinder 1: } 6.17 \\
\text { Cylinder 2: } 6.23 \\
\text { Cylinder 3: } 6.73\end{array}$ & 6.38 \\
\hline
\end{tabular}

Prior to executing each test point, the engine was warmed to $90^{\circ} \mathrm{C}$ coolant and oil temperature using dummy plugs blanking the access sleeves, in order to prevent fouling of the borescope optics. The engine was then shutoff and optics installed in the engine as promptly as possible (less than 8 minutes), before restarting and commencing the test.

In the case of condition 1, the engine was run at the test condition and a sequence of 10 $\mathrm{kHz}$ high speed video was captured, alongside measured data to form the baseline condition for this work. Data was also captured in the same way for condition 3, which did not feature a cylinder deactivation. In the case of condition 2 , preliminary exploratory image capture had indicated that there was no significant image data to be captured at the transition into the deactivated state in cylinder 1 so image data was captured during the reactivation of the deactivated cylinder. Once the test engine running condition was set using the dynamometer control system, the VDE was activated using the ATI Vision PCM interface software. Image capture was commenced at $10 \mathrm{kHz}$ immediately prior to the reactivation of cylinder 1 , in order to capture the complete transition. 


\section{VDE de-activation procedure}

The transition of the engine from full to reduced displacement operation (i.e. engine operating condition 1 to 2 ) involved the actuation of a mechanism in the valve rockers to prevent them from opening either inlet or exhaust valves. This actuation was controlled by the PCM to occur immediately following a combustion event, such that a burnt charge was trapped within the cylinder. The charge was then repeatedly compressed and expanded, forming a so-called gas spring, with much of the compression work being returned to the crank by the expansion stroke. The in-cylinder pressure in the engine cycles following a cylinder deactivation event is plotted in Figure 3; it can be seen that there was a reduction in the peak pressure at each top-dead centre (TDC) because of thermal losses and blow-by. The continually reducing minimum in-cylinder pressure required a strategy of cylinder recharging, to prevent the in-cylinder pressure dropping so low as to have potentially led to the ingress of crankcase oil into the cylinder. The recharge process involved reactivating the cylinder briefly, before again deactivating and was found to occur every 60 seconds of operation at $1600 \mathrm{rpm}$.

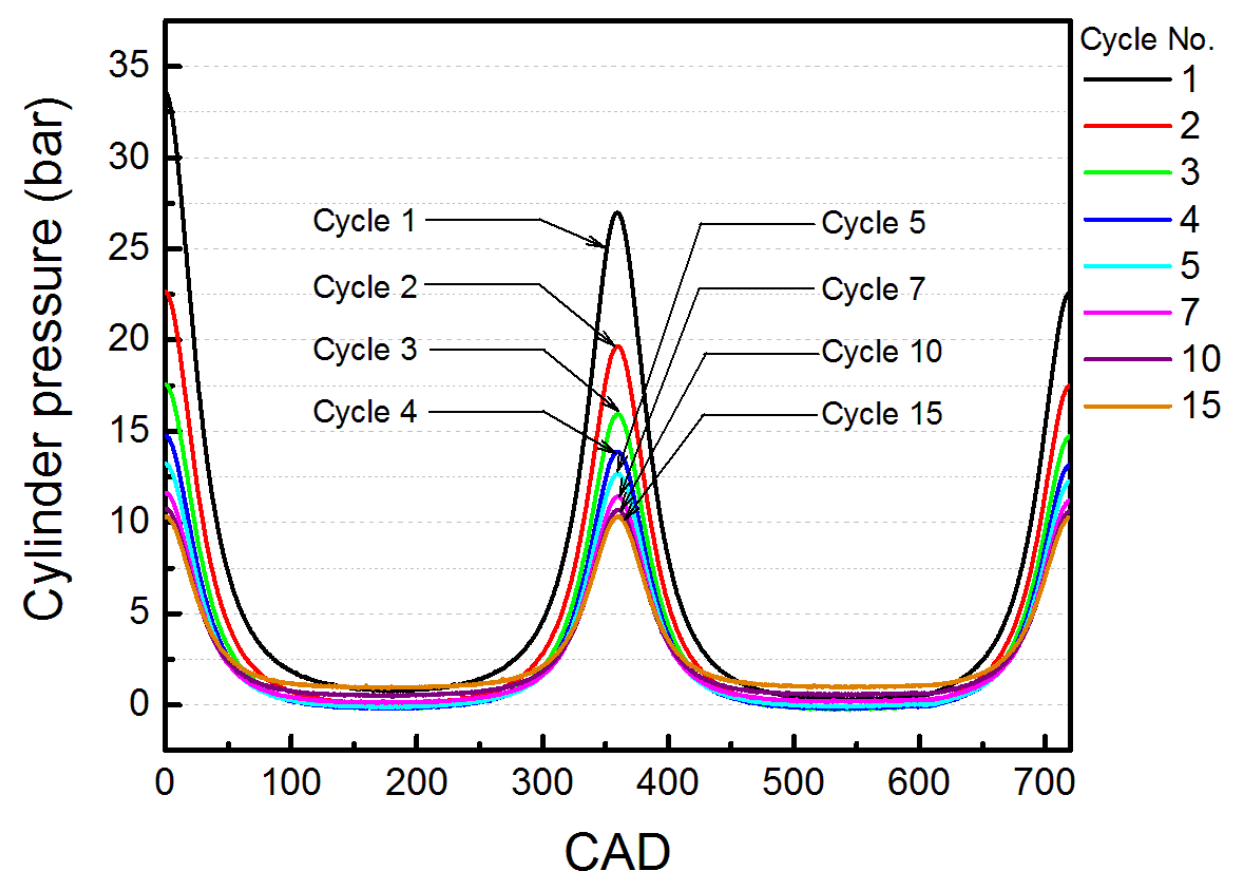

Figure 3 - In-cylinder pressure for engine cycles immediately following cylinder deactivation (de-activated cylinder)

\section{Results and discussion}

The engine performance and emissions data captured during the test campaign are firstly considered here, to illustrate the impact of the cylinder deactivation and IMEP on the engine outputs (for condition 2 , the measurements are made during the deactivated state). Secondly, the in-cylinder conditions of the switchable cylinder (No. 1) are discussed during the VDE reduced displacement cylinder deactivation, as well as the fuel spray and combustion events that follow shortly after reactivation of the cylinder. 


\section{Engine emissions for tested operating conditions}

Figure 4 shows the brake specific fuel consumption (BSFC) measured for each engine condition during testing. It is apparent that there is a definite improvement in BSFC when switching the engine from full displacement mode (test condition 1) to reduced displacement mode (test condition 2), with the BSFC reducing from $291.8 \mathrm{~g} / \mathrm{kWh}$ to 264.3 $\mathrm{g} / \mathrm{kWh}$. This can be explained as the effect of the reduction in pumping loss brought about by the wider throttle opening required in the reduced displacement condition. There is a further small reduction in BSFC in test condition $3(262.1 \mathrm{~g} / \mathrm{kWh})$, which produced a greater torque than the other two conditions. The improvement seen here is brought about by a further reduction in pumping losses as a result of the increased throttle opening required to bring about the torque output, which forced the engine into a more efficient region of operation and also made the heat loss of the engine proportionately less significant.

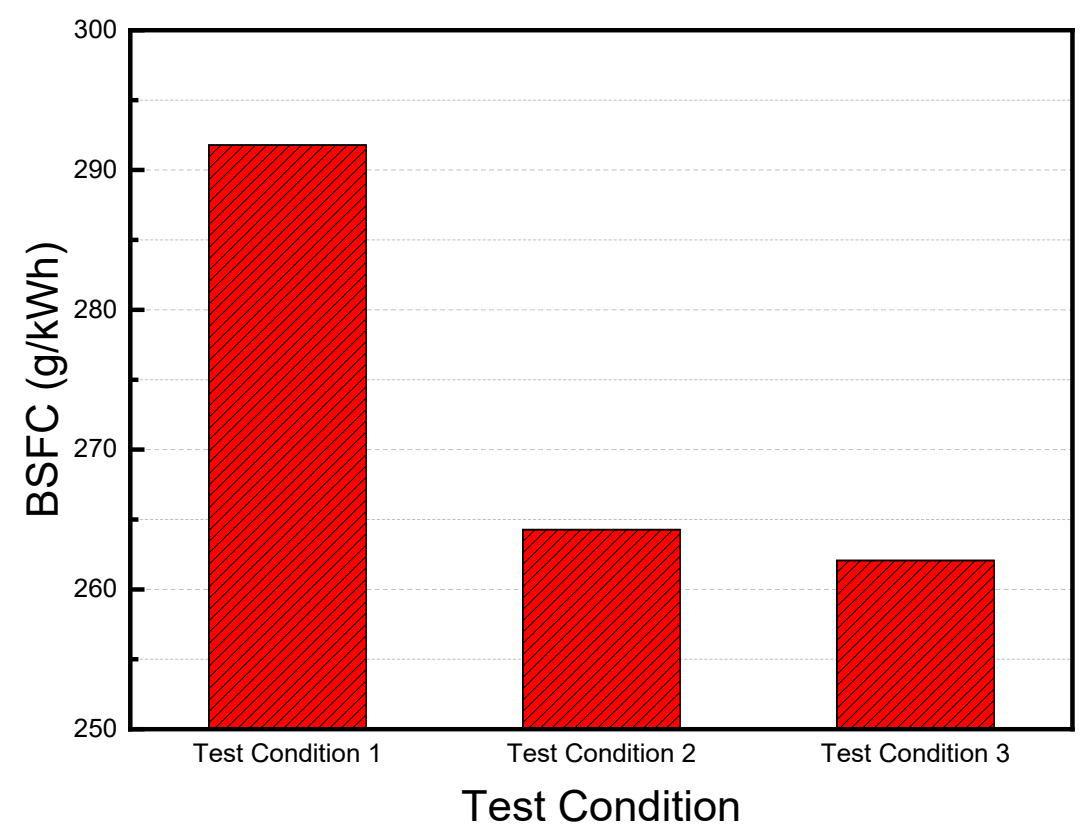

Figure 4 - Comparison of brake specific fuel consumption

The average air fuel ratio (AFR) of the three test conditions is shown in Figure 5, where it can be seen that test condition 2, the deactivated condition, has a higher and therefore leaner AFR than the other conditions. This $3 \%$ increase of the AFR is a feature of the engine control strategy and that is related to the gaseous emissions output measured prior to the engine's catalytic convertor, illustrated in Figure 6. 


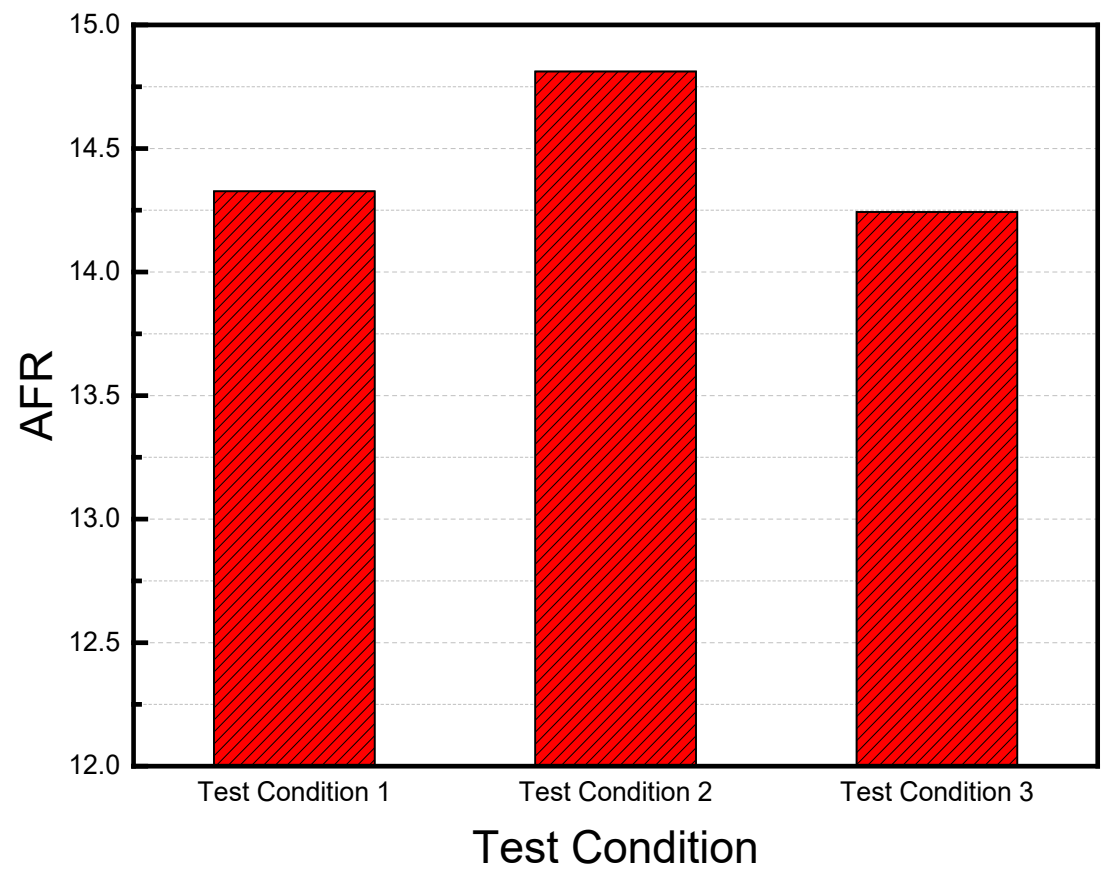

Figure 5 - Average air/fuel ratio

Considering $\mathrm{HC}$ emissions (Figure 6) it can be seen that the $\mathrm{HC}$ level of test condition 2 is lower in comparison to test conditions 1 and 3 . This relationship is due to higher in-cylinder combustion temperatures, resulting from the increase in IMEP compared to the full displacement running condition 1, combined with a greater abundance of available oxygen than test condition 3, evident from the greater AFR seen at condition 2 (Figure 5). These results align with the $\mathrm{CO}$ trend which also tends to be reduced by high temperatures and an abundance of oxygen to support oxidation reactions. It is also notable that the $\mathrm{HC}$ and $\mathrm{CO}$ levels of test condition 3 are lower than that of condition 1. This was considered to be due solely to the increase of in-cylinder temperature resulting from its higher IMEP. 


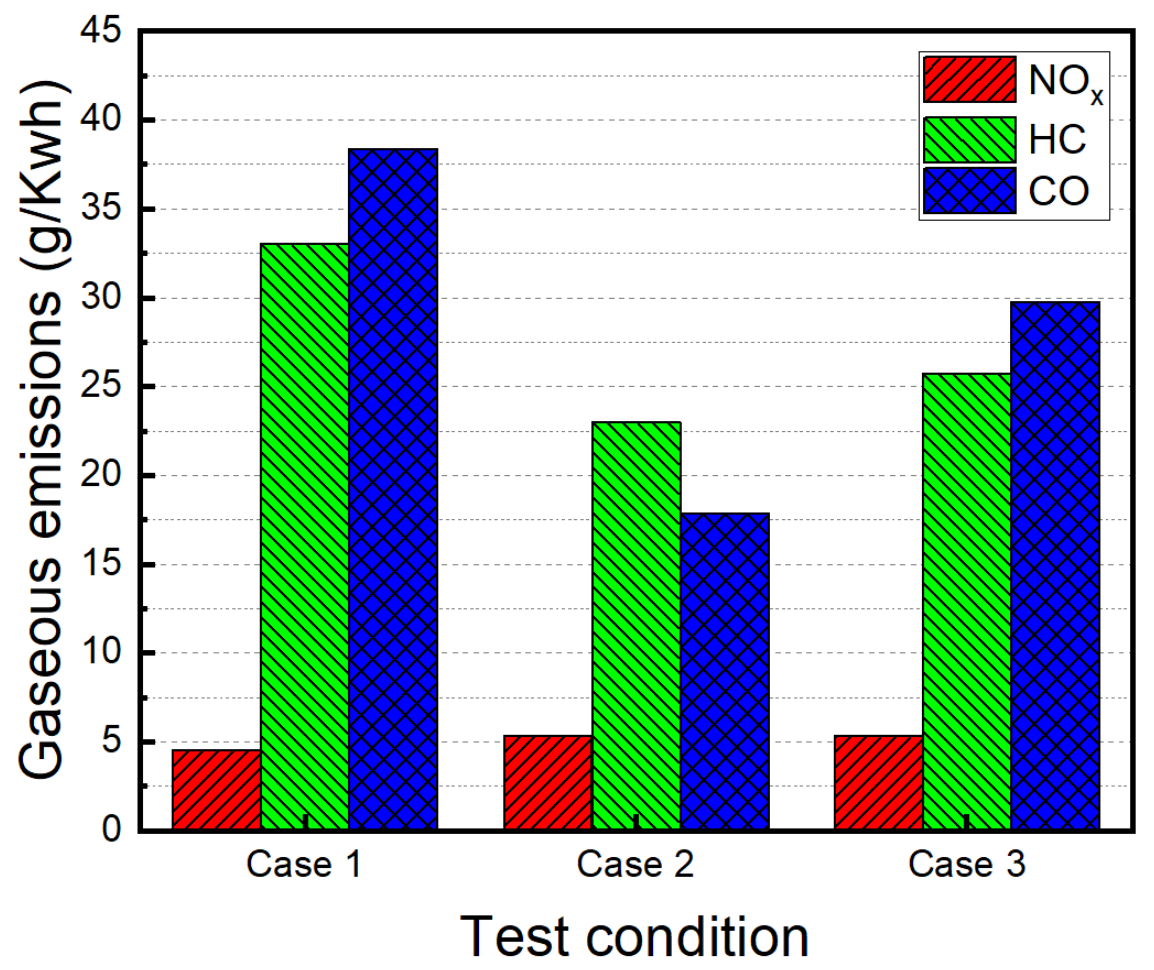

Figure 6 - Comparison of average emissions

The excess air present in condition 2 from the 3\% increase in AFR (apparent from Figure 5) leads to lower emissions of $\mathrm{HC}$ and $\mathrm{CO}$ in comparison to condition 1 and 3.

It can be seen that the $\mathrm{NO}_{\mathrm{x}}$ emission is increased by the engine operating in test conditions $2(17 \%)$ and $3(16 \%)$, in comparison to test condition 1 . This is due to the IMEP at these conditions being notably higher than that of test condition 1, which will result in a higher in-cylinder temperature, subsequently driving the high temperature dissociation reactions which lead to NOx formation.

The average PN emissions measured during testing at the three conditions are shown in Figure 7, where it can be seen that test condition 2, the condition with cylinder 1 deactivated, produces the highest levels of PN emissions. Figure 8 illustrates the time history of the sampled PN emission during a test at condition 2; Figure 8a shows the history over a larger time scale, where its operation in deactivated mode can be seen to increase the level of PN emissions, which then continues to be highly transient in nature throughout. There are a number of cylinder recharge events (lasting 71 cycles), where the cylinder is deactivated and the reactivated to help prevent the minimum cylinder pressure from dropping too low and causing the ingress of oil from the crankcase into the cylinder. The engine was operated with what was considered a design intent cylinder recharge strategy of 60 s recharge intervals. During the short reactivation period in the deactivation operation, the fuel injection and valves were activated in order to refresh the trapped combusted gas in the cylinder in subsequent cycles. Figure $8 \mathrm{~b}$ shows a section of the same data over a smaller timescale, allowing a more detailed analysis of the PN increase, which can be seen to rise by an order of magnitude at its initial peak, before steadily reducing. 
To further assess the particulate matter emissions, Figure 9 presents the size and number distribution. As was already evident from Figure 7, test condition 2 can be seen to exhibit a higher quantity of particulate matter. However, there is evidence of a significant increase in the larger particles. This increase could indicate the occurrence of more significant spray impingement and subsequent pool fires due to the extension of injection duration required in the increased specific load condition.

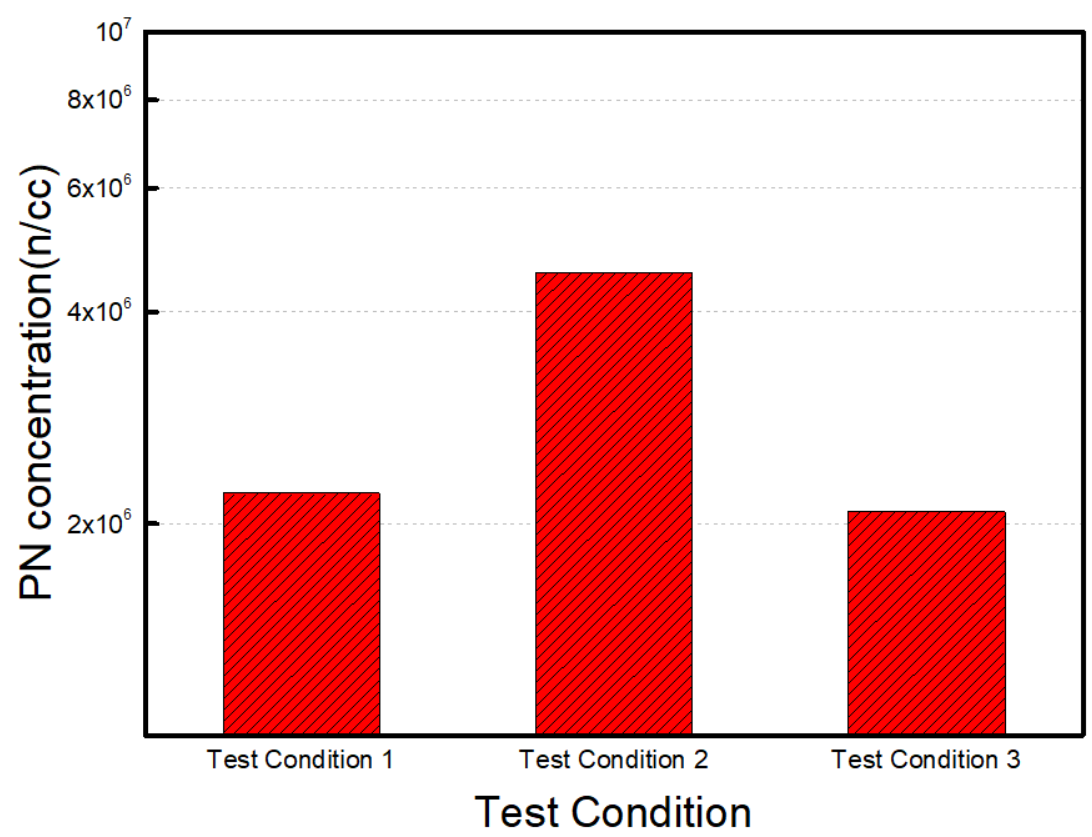

Figure 7 - Average PN emissions

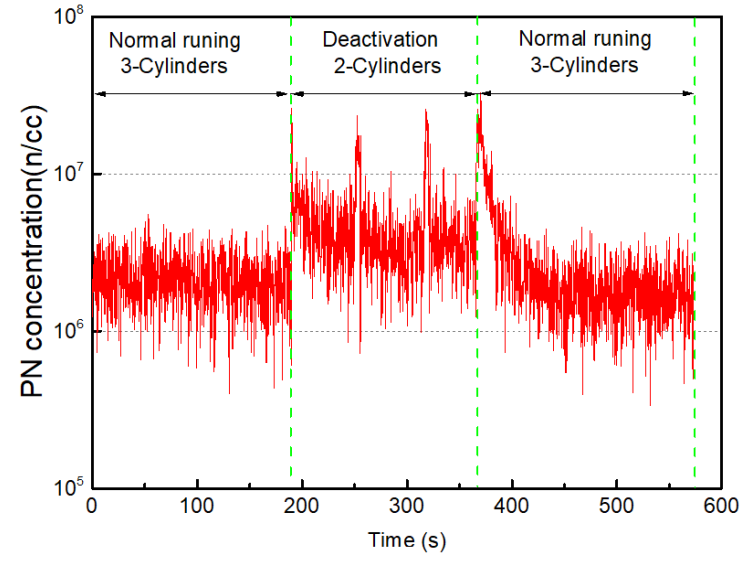

(a)

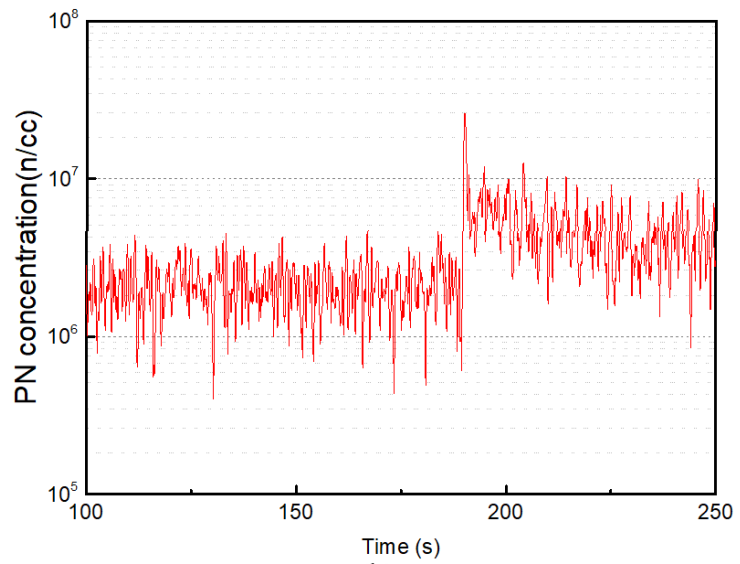

(b)

Figure 8 - Engine-out PN emissions for test condition 2 


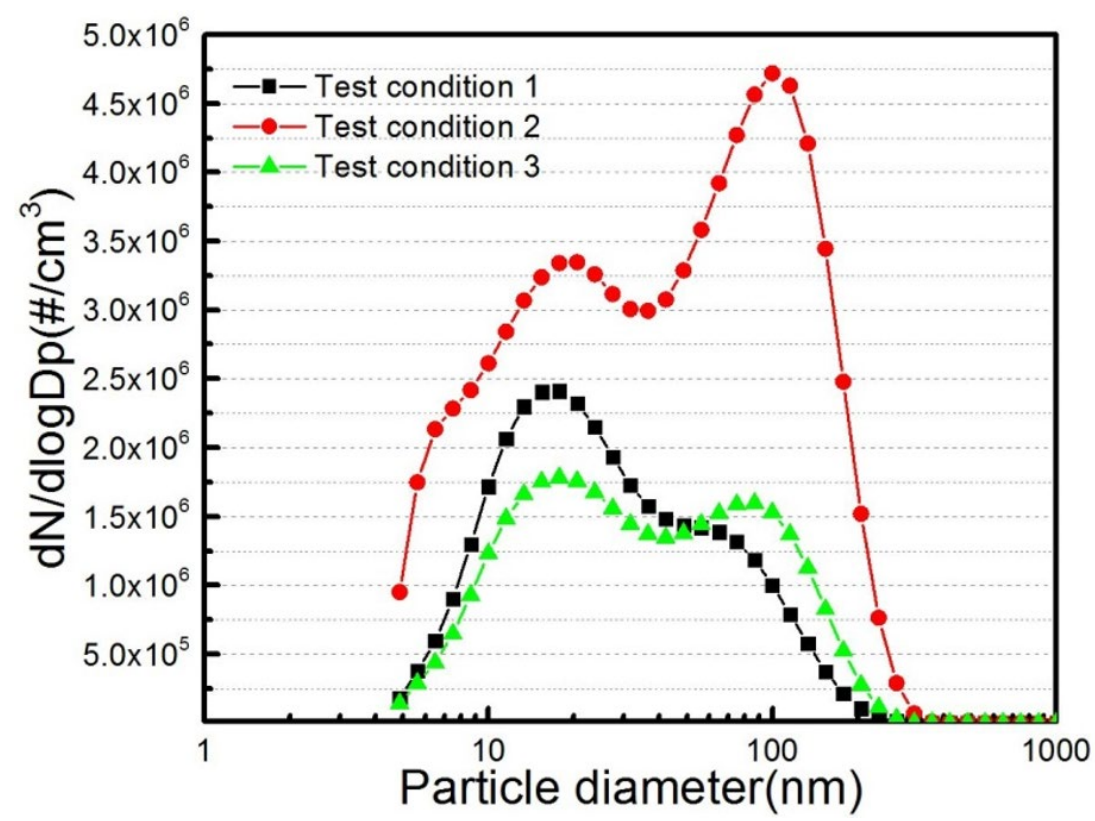

Figure 9 - Particle size distribution for each test condition

\section{Image analysis of VDE events}

The images presented in this section, captured with the experimental configuration described previously, illustrate the events occurring both immediately following deactivation of the VDE cylinder and also after its reactivation. Figure 10 illustrates the view captured by the borescope imaging system, identifying the key areas that the reader will observe in the subsequent images which are presented.

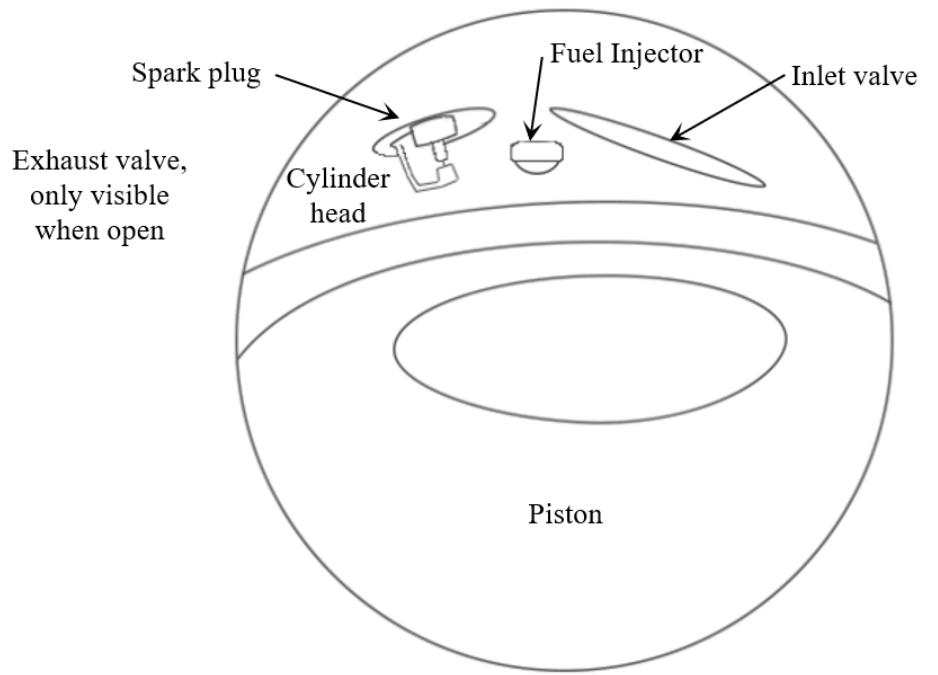

Figure 10 - Simplified illustration of cylinder layout as seen from borescope

The in-cylinder images captured immediately following the deactivation event are shown in Figure 11 and indicate that a level of condensation develops because of the falling temperature and pressure, first apparent after approximately 8 cycles of the engine. The in- 
cylinder view captured at $173^{\circ}$ ATDC on the $1^{\text {st }}, 8^{\text {th }}$ and $20^{\text {th }}$ cycles following deactivation of the cylinder illustrates the change in appearance of the in-cylinder condition. After the $20^{\text {th }}$ cycle, the level of condensation appeared consistent between cycles. The stable amount of condensation after cycle 20 indicates that temperature and pressure in the cylinder has reached an equilibrium. This observation is consistent with what was observations in Allen et. al. ${ }^{1}$.

Images captured of combustion events immediately following reactivation of the VDE cylinder, i.e. transition back to test condition 1, are presented in Figure 12. Consideration of the images indicates that the in-cylinder combustion conditions were significantly different between consecutive cycles. In the first two cycles after reactivation, very bright diffusive flame on the left side of the piston is observed. This is indicative of a localised rich region and is consistent with the fuel plume impingement location. There could also be an additional contribution because of oil ingress due to the very low in-cylinder pressures present during the deactivated period, as observed in Figure 3. These areas of diffusive flame are believed to be the site of particulate matter production and they correlate strongly with the peaks in measured PN presented in Figure 8. Those cycles exhibiting significant diffusion flame luminosity in Figure 12 correspond to an increased IMEP as presented in Figure 13. The main reactivation transient appears to be completed after cycle 6 when considering IMEP (Figure 13(d)) though some cycle to cycle variation may still exist.
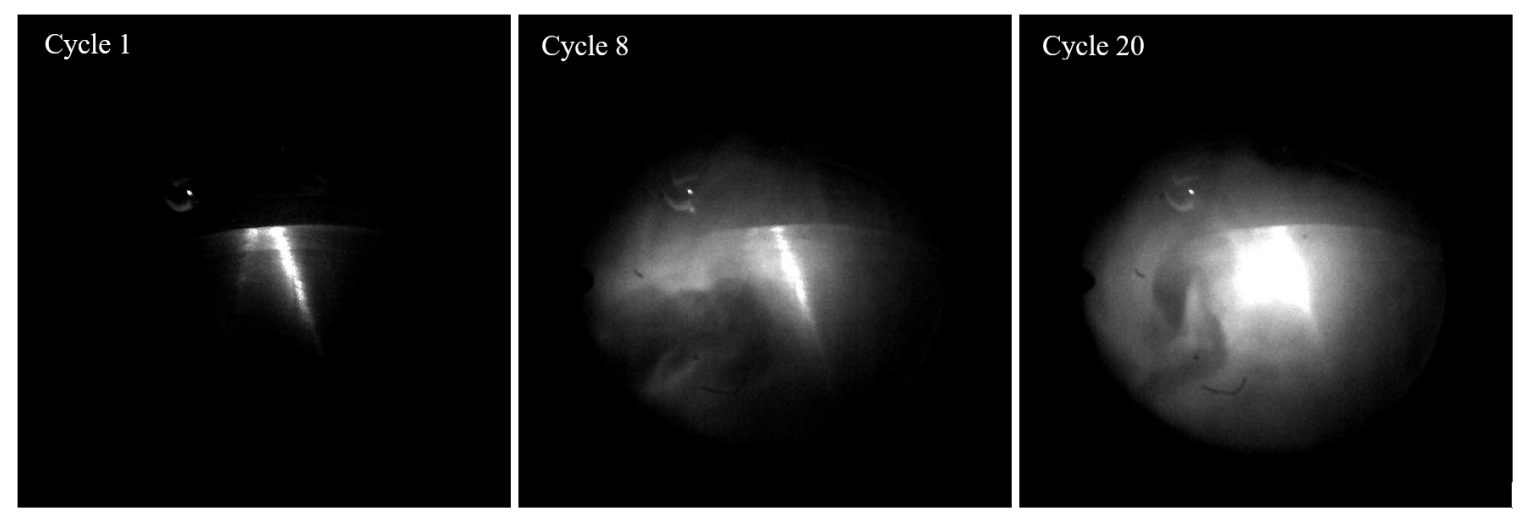

Figure 11 - In-cylinder images, captured at $173^{\circ}$ ATDC. Text indicates number of cycles after deactivation 

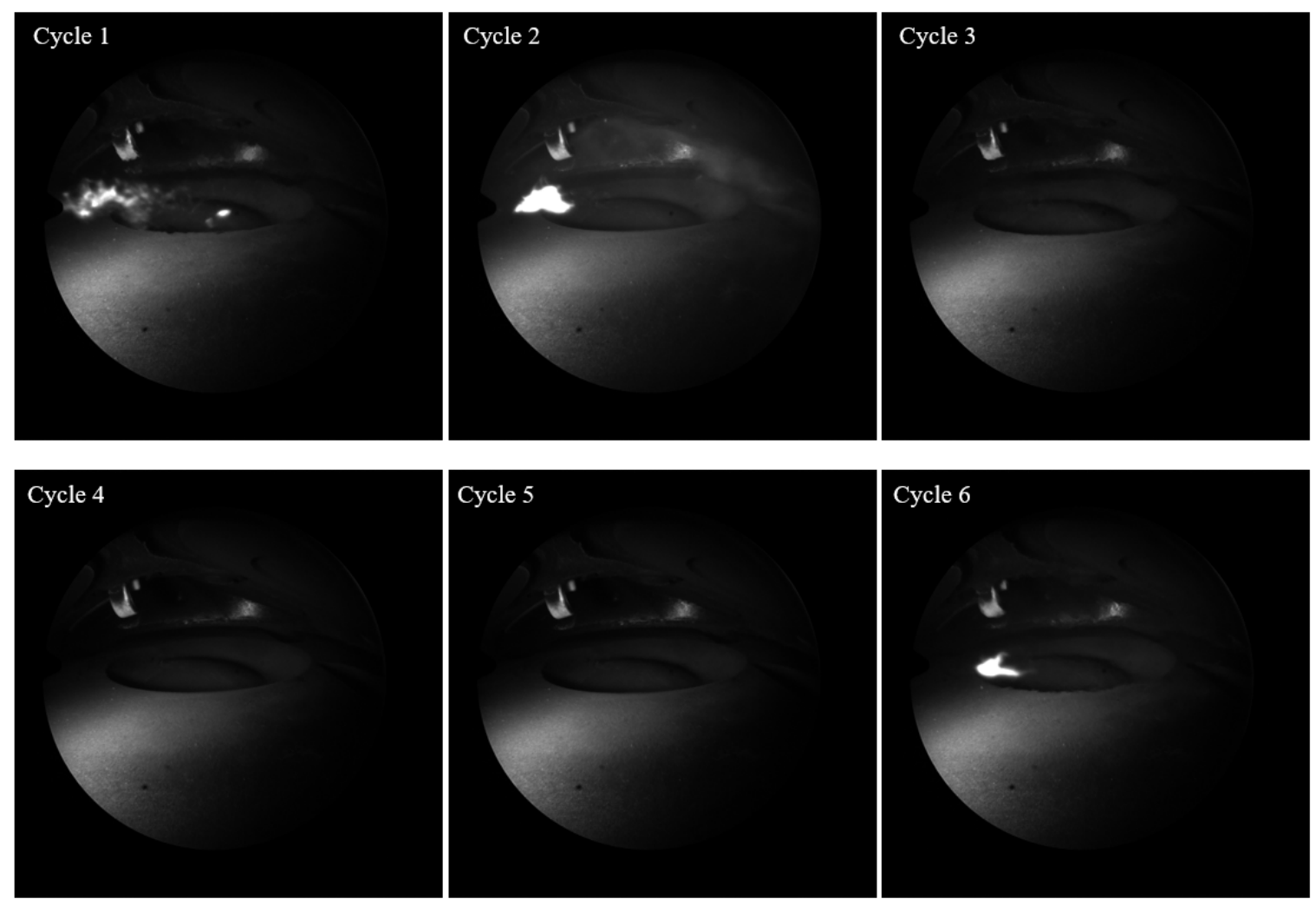

Cycle 6

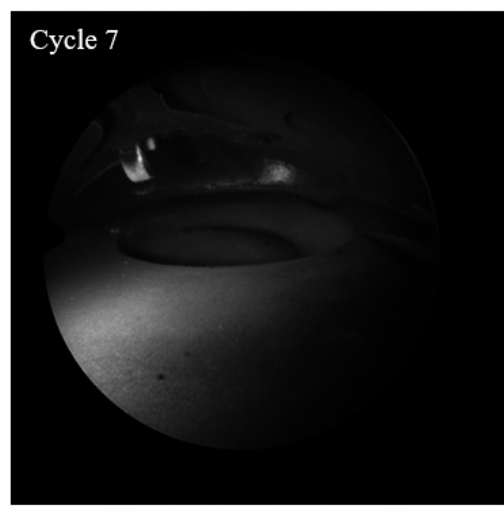

Cycle 8

Cycle 9

Figure 12 - Images of combustion at TDC. Text indicates cycles after reactivation 

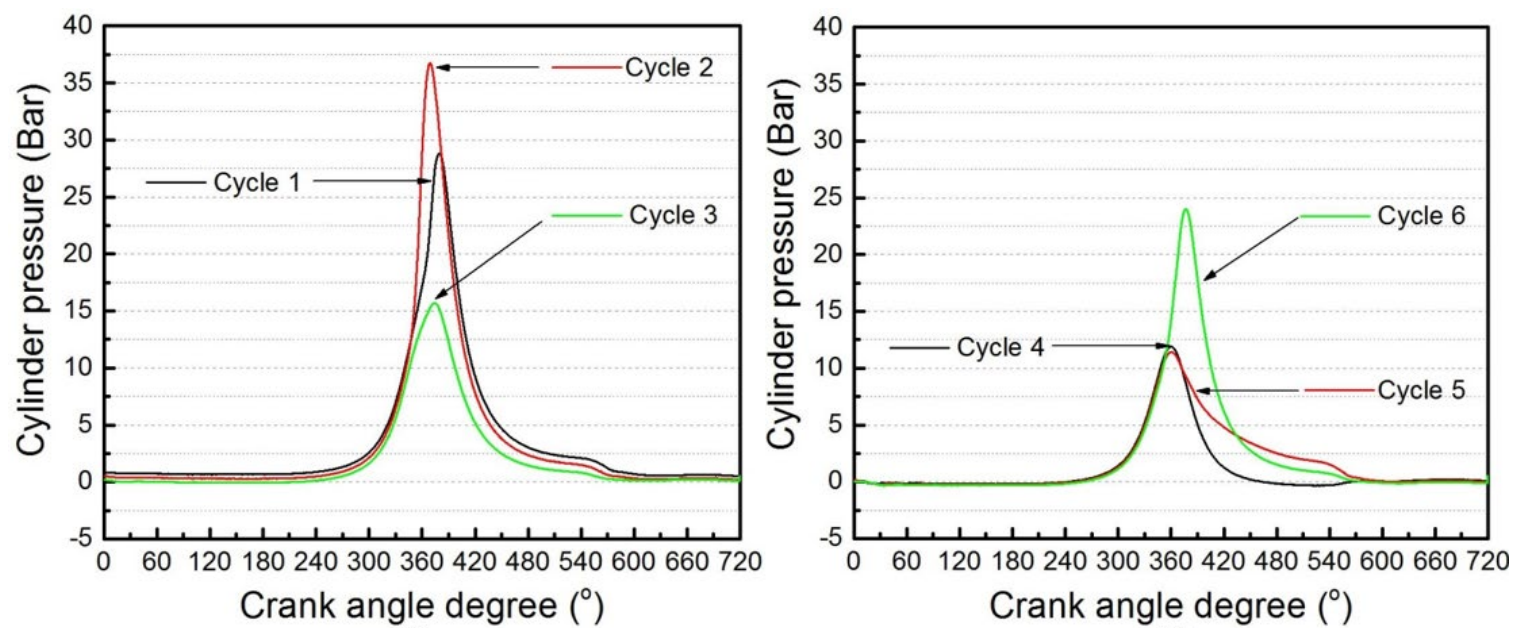

(a)

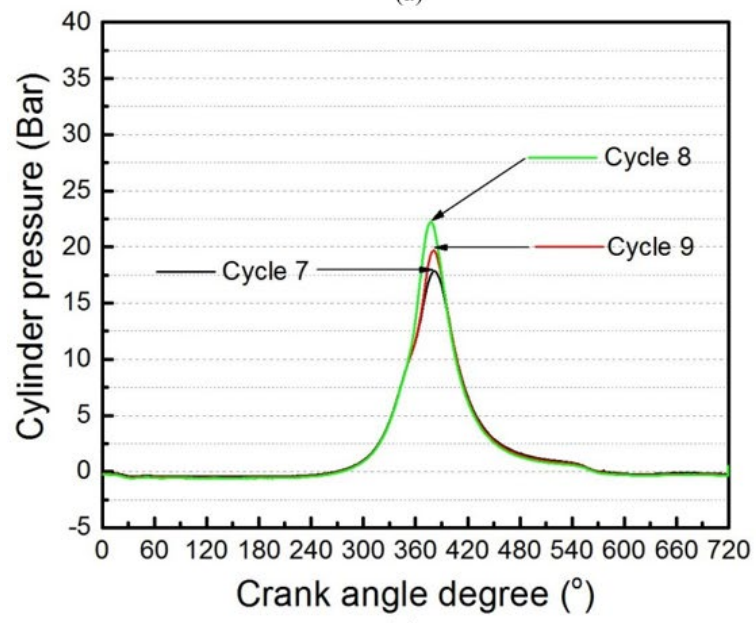

(c)

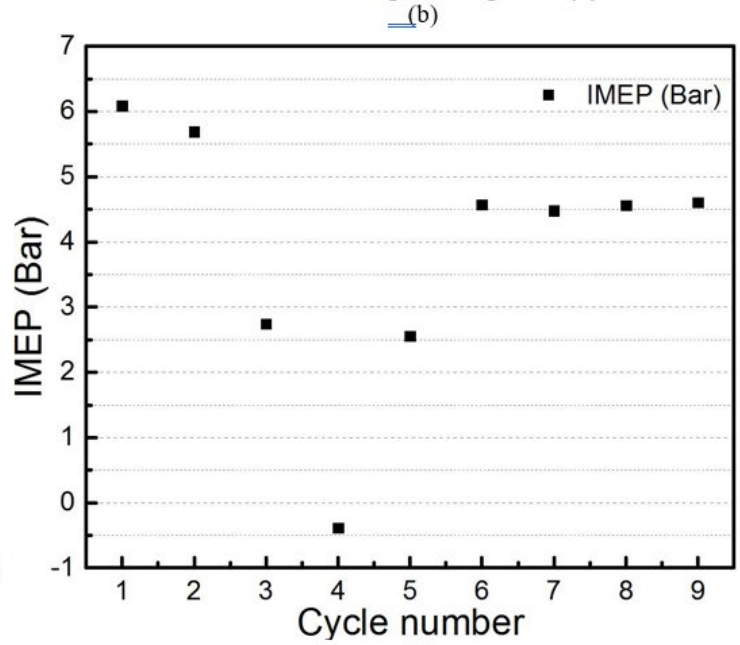

(d)

Figure 13 - In-cylinder pressure and IMEP for first nine cycles following reactivation

Figure 14 shows spray images captured at $266^{\circ}$ ATDC from a number of cycles following reactivation of the VDE cylinder. Subjective consideration of these images, combined with analysis of the image intensity, indicated little difference between individual frames and suggested a very similar fuel spray was delivered on each cycle. These results would therefore suggest that the fuel spray morphology is not the most significant factor affecting the cycle-to-cycle combustion variation after reactivation. The closed-loop control of the engine relies on signals from the flow rate sensor and lambda sensor from its previous cycles. During the 9 cycles $(0.675 \mathrm{~s}$ at $1600 \mathrm{rpm})$ of operation after reactivation, the intake manifold pressure drops from 0.85 bar to 0.63 bar. This rapid rate of decrease of intake manifold pressure leads to inaccurate control input of these parameters for the initial 9 cycles. As a result, some variation in the combustion performance is observed as indicated by Figure 12 and Figure 13. While other factors may be at play, such as thermal transients, the rapid change in control inputs is thought to be the most predominant in affecting cycleto-cycle combustion variation after reactivation. 

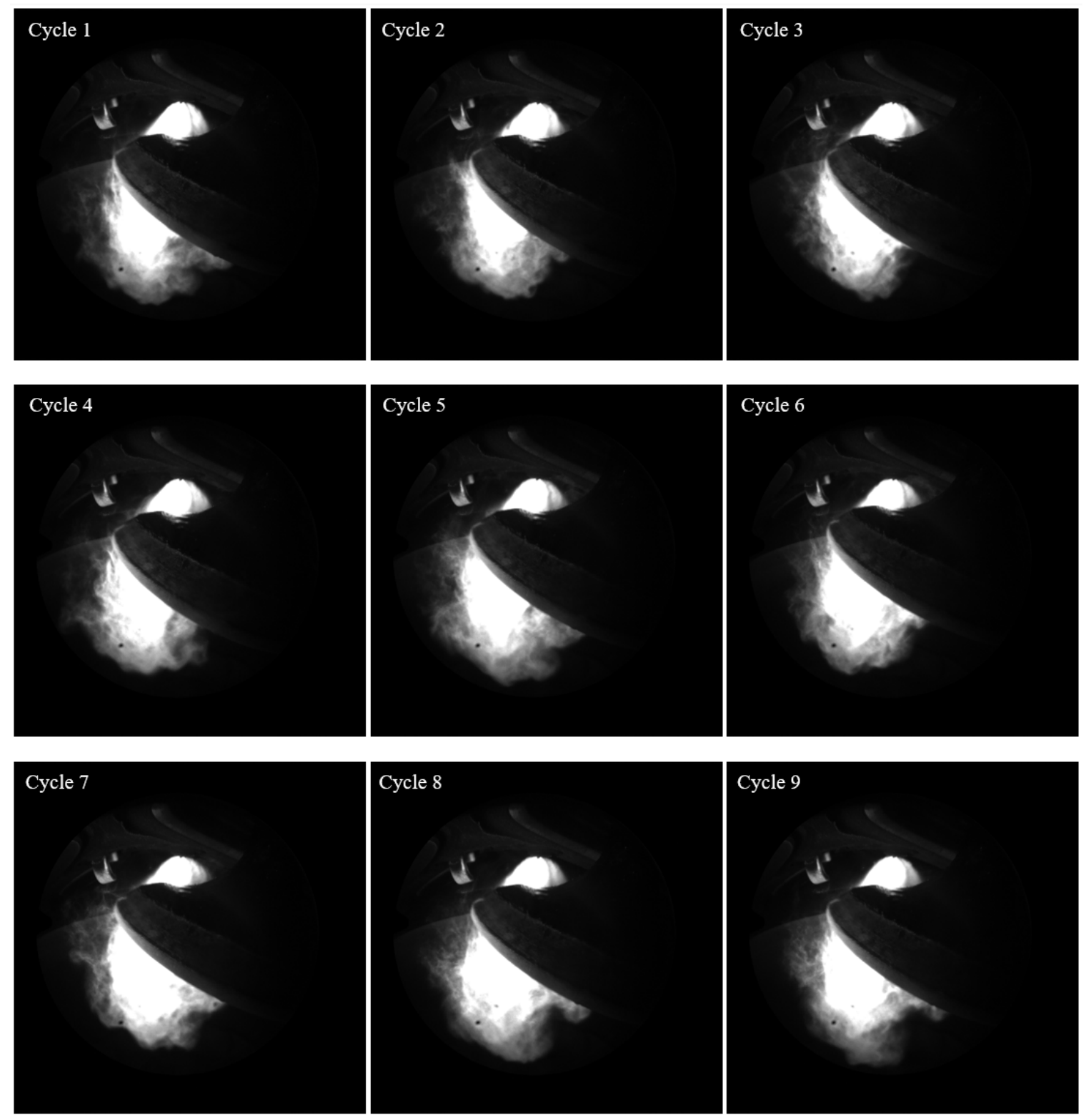

Figure 14 - Images of spray, captured at 266 deg BTDC. Text indicates number of cycles after reactivation

\section{Conclusions}

This work has studied the impact of VDE cylinder deactivation on fuel consumption and emissions of a 1.0 1, 3-cylinder GTDI engine. Emissions and performance data were collected running the engine at steady state in three different conditions; under normal operation of all three cylinders, with the VDE cylinder deactivated and again under full three cylinder operation, but with the IMEP of the deactivated condition. During deactivation and immediately following reactivation, borescopic images were captured in 
the VDE capable cylinder, allowing understanding of the fuel spray and combustion to be gained and combined with the recorded data. It is believed that this type of imaging has not been reported previously. The following major conclusions were drawn from this study:

1. In agreement with literature, the implementation of VDE at low load resulted in an improvement in fuel economy. At the condition tested, 1600 RPM and $30 \mathrm{Nm}$, reductions of $9 \%$ was observed for fuel consumption together with a reduction in $\mathrm{HC}$ and $\mathrm{CO}$ emissions. However, the associated increase in combustion temperature led to a $17 \%$ increase in NOx emissions.

2. After deactivation, the peak and minimum in-cylinder pressure in the deactivated cylinder rapidly reduce due to heat loss and air leakage, necessitating the cylinder to be reactivated briefly in order to prevent ingress of oil from the crankcase to the cylinder.

3. PN emissions increase by $100 \%$ during the deactivation periods compared to the normal running condition. An increase in particle number is observed in both nucleation mode and accumulation mode, with in the increase in the accumulation mode level being more significant.

4. A number of cycles exhibiting diffusive flame was observed immediately following re-activation. This corresponded to an increase in IMEP for those cycles, followed by a reduction. This settles to a typical value after approximately 5 cycles.

5. Across the first 9 cycles after reactivation, a link between diffusive combustion and high peak in-cylinder pressure was apparent. This indicates the difficulty of control for these cycles soon after reactivation, where an unstable air intake condition is likely to be present.

\section{References}

1. Allen CM, Gosala DB, Shaver GM, et al. Comparative study of diesel engine cylinder deactivation transition strategies. Int J Engine Res 2019; 20: 570-580.

2. Moore W, Foster M, Lai M-C, et al. Charge Motion Benefits of Valve Deactivation to Reduce Fuel Consumption and Emissions in a GDi, VVA Engine. SAE Technical Paper 2011-01-1221. DOI: 10.4271/2011-01-1221.

3. Millo F, Mirzaeian M, Luisi S, et al. Engine displacement modularity for enhancing automotive s.i. engines efficiency at part load. Fuel 2016; 180: 645652.

4. Kuruppu C, Pesiridis A, Rajoo S. Investigation of Cylinder Deactivation and Variable Valve Actuation on Gasoline Engine Performance. SAE Technical Paper 2014-01-1170 DOI: 10.4271/2014-01-1170.

5. Zammit JP, McGhee MJ, Shayler PJ, et al. The effects of early inlet valve closing and cylinder disablement onfuel economy and emissions of a direct injection diesel engine. Energy 2015; 79: 100-110.

6. Zammit JP, McGhee MJ, Shayler PJ, et al. The influence of cylinder deactivation on the emissions and fuel economy of a four-cylinder direct-injection diesel engine. Proc Inst Mech Eng Part D J Automob Eng 2014; 228: 206-217.

7. Boretti A, Scalco J. Piston and Valve Deactivation for Improved Part Load Performances of Internal Combustion Engines. SAE Technical Paper 2011-010368 DOI: 10.4271/2011-01-0368. 
8. Stuhldreher M. Fuel Efficiency Mapping of a 2014 6-Cylinder GM EcoTec 4 . 3L Engine with Cylinder Deactivation. SAE Technical Paper 2016-01-0662 DOI: 10.4271/2016-01-0662.

9. Leone TG, Pozar M, Co FM. Fuel Economy Benefit of Cylinder Deactivation Sensitivity to Vehicle Application and Operating Constraints. SAE Transanctions (2001), 2039-2044

10. Abas M, Martinez-Botas R. Engine Operational Benefits with Cylinder Deactivation in Malaysian Urban Driving Conditions. SAE Technical Paper 201501-0983 DOI: 10.4271/2015-01-0983.

11. Moore W, Foster M, Hoyer K. Engine Efficiency Improvements Enabled by Ethanol Fuel Blends in a GDi VVA Flex Fuel Engine. SAE Technical Paper 201101-0900 DOI: 10.4271/2011-01-0900.

12. Allen CM, Joshi MC, Gosala DB, et al. Experimental assessment of diesel engine cylinder deactivation performance during low-load transient operations. Int $J$ Engine Res 2019; 146808741985759.

13. Ramesh AK, Shaver GM, Allen CM, et al. Utilizing low airflow strategies, including cylinder deactivation, to improve fuel efficiency and aftertreatment thermal management. Int J Engine Res 2017; 18: 1005-1016.

14. Ding C, Roberts L, Fain DJ, et al. Fuel efficient exhaust thermal management for compression ignition engines during idle via cylinder deactivation and flexible valve actuation. Int J Engine Res 2016; 17: 619-630.

\section{Acknowledgements}

The authors would like to acknowledge the financial support of the Advanced Propulsion Centre (APC) for this work which was undertaken as part of TSB/APC project number 101891. The authors also wish to acknowledge Ford Motor Company and Continental Automotive for their technical support of the work. 